\title{
Volatility as an Asset Class - A Valuable Portfolio Diversifier in Volatile Times?
}

\author{
Prof. Dr. Pascal Gantenbein, Dr. Andreas Rehrauer
}

\begin{abstract}
This article examines the feasibility of using volatility as an asset class to diversify equity portfolios. Especially exchange-traded volatility products targeted at retail investors promise convenient but effective equity hedging. This study looks under the surface of these seemingly simple products, and backtests them in extensive portfolio diversification studies. We apply a wide range of test settings, including different volatility weights, product maturities, time periods, rebalancing patterns, and dynamic allocation strategies while adopting the perspective of U.S. equity investors over the volatile period from 2006 to 2011. We find that volatility exposures of up to $10 \%$, implemented through mid-term volatility products or with a straightforward dynamic allocation strategy based on detecting trends in implied volatility, would have benefited equity portfolios in most scenarios.
\end{abstract}

Index Terms - volatility; financial crisis; hedging with volatility; VIX; portfolio diversification

\section{INTRODUCTION}

$\mathrm{D}$ URING the 2008 financial crisis, many asset classes typically held to diversify equity portfolios failed in doing so precisely when it was needed most. The main reason was that during the crisis, asset class correlations rose substantially. Portfolio diversification therefore was far less effective than anticipated, and many investors faced massive losses when most asset classes plummeted at the same time. This phenomenon is well documented. It is stated, for example, that in 2008 "many assets that are typically considered effective equity diversifiers also faced precipitous losses", including alternative asset classes like hedge fund strategies and commodity indices [1]. Further studies reporting increasing asset class correlations or diversification failures during crises are [2], [3], [4], and [5].

Not surprisingly, in the aftermath of the 2008 financial crisis the quest for crisis robust assets classes actually living up to their diversification promise, i.e., keeping a negative correlation also in adverse markets, intensified. In the course of that search, volatility emerged as such a promising asset class.

Volatility had long been considered merely a statistical risk metric for returns on securities.

Manuscript received June 22, 2013

Prof. Dr. Pascal Gantenbein is head of the Henri-B.-Meier Department of Financial Management, University of Basel, Switzerland (e-mail: pascal.gantenbein@unibas.ch).

Dr. Andreas Rehrauer was Ph.D. student at the Henri-B.-Meier Department of Financial Management, University of Basel, Switzerland. Corresponding author (phone: +41-44-3608738; fax: +41-44-3608686; e-mail: andreas.rehrauer@unibas.ch).
Over the last few years, however, volatility has also become an investable asset class in its own right and is increasingly demanded by and targeted at broader groups of investors. Although volatility does not produce direct returns such as dividends or interest (for this lack of intrinsic return generation and for other reasons, there are critics denying volatility the status of an asset class; see, e.g., [7]), it is currently extolled as an effective portfolio-diversifying asset class, and the product landscape for trading possibilities in volatility is evolving rapidly, as described in [5] and [8].

The rise of volatility as an asset class started with the introduction of the Chicago Board Options Exchange (CBOE) Volatility Index (ticker symbol: VIX; also see [9] and [10] for details on the VIX, and [11] for its white paper) in 1993, which later turned into the premier volatility benchmark and also became a starting point of a number of tradable volatility derivatives targeting a wider range of investors. From a niche strategy for institutional investors, it became an asset class accessible to retail investors [6]. This evolution came to a climax in January 2009 when the first exchange traded notes (ETNs) on volatility futures were launched, which made volatility readily investable for basically any investor.

Volatility, at least when represented by the non-tradable VIX, has been shown to theoretically offer a number of very appealing properties to investors, most importantly a robust negative correlation with most asset classes, especially equities. At the same time, however, there remains doubt concerning the extent to which these attractive properties can be successfully passed on to the tradable volatility products derived from the VIX. Also, assuming that diversification properties could be passed on, it still has to be determined which volatility products and implementation strategies work best, which markets and circumstances are most conducive to volatility-diversification, and how much judgment and unerring market timing is needed?

These questions are considered more relevant than ever before. With the success of volatility ETNs, access to volatility as an asset class is made very easy, and investor groups that formerly would not have participated in complex volatility investment are now attracted. At the same time, studies focusing on the volatility products targeted at retail investors are missing, apart from the studies produced by banks' marketing departments. All too often, it is concealed that futures-based derivative securities, which have complex properties, substantial risks and idiosyncratic behavior, exhibit 
features different from the seemingly simple volatility ETNs marketed towards retail investors.

This article's contribution is twofold. First, it illustrates the behavior of volatility as an asset class from a retail investor's perspective. To that end, an extensive portfolio diversification study is presented and discussed. The study extends the current literature by focusing specifically on volatility ETNs, thereby providing insights that are of direct relevance to retail investors. Second, we evaluate dynamic volatility strategies and find a successfully backtested implementation strategy based on trends in implied volatility.

Given the myriad of possibilities for harnessing volatility for investment purposes, it is essential to focus on a precisely defined object of investigation. Within the scope of this article, we investigate long volatility strategies implemented via simple ETNs based on VIX futures with different maturities. Out of scope are short volatility strategies (e.g., volatility risk premium strategies based on the difference between realized and implied volatility), long volatility strategies using products other than ETNs (e.g., strategies based on individual futures or option contracts or more exotic products like straddles, more complex ETNs that are leveraged, for example, or imply a dynamic strategy, see [12] for an overview, or products with underlying volatility indices other than VIX.

This article is organized as follows. Section II positions the article within the context of the related literature. Section III describes this diversification study's approach and the data. Section IV presents the results. Section V concludes.

\section{LITERATURE}

Volatility as an asset class is increasingly discussed in the literature. With the emergence of new volatility-based products and the availability of sufficient recorded trading data, an increasing number of diversification studies use backtesting to analyze these products. However, many studies restrict their consideration of volatility to the popular, but non-investable VIX spot index and therefore produce theoretical results that are unrealistic, mostly exaggerated and rarely of relevance to practitioners; see, e.g., [13], [14], [15], [16], and [17]. Some studies represent volatility through a particular self-made options- or futures-based investment strategy, which is rather difficult to replicate and frequently subject to a number of assumptions, e.g., with respect to the futures rolling mechanism; see, e.g., [2], [5], [18], [19], [20], [21], [22], [23], and [24]. To date, very few studies investigate volatility in relation to ETNs or assess its value for a strategy used by retail investors. One exception is [8], which indirectly tackles this subject in that it inspects the diversification properties of the S\&P 500 VIX Futures Indices in an equity portfolio represented by the S\&P 500 for the period 2005 to 2010 . It reports a strong negative correlation between the VIX futures indices and the S\&P 500, which spiked at times of crisis.

However, empirical findings on volatility exposure through ETNs are very limited to date. Moreover, available studies lack consensus over fundamental questions, e.g., whether it is truly advantageous to add these instruments to a portfolio, what circumstances would make doing so advantageous, and which strategies could best implement such instruments.

Furthermore, there are only few examples in the literature where volatility exposure is strategically adjusted. In one part of [20], for example, an allocation strategy is proposed that tries to take advantage of the mean-reverting nature of volatility. Similarly, [2] also proposes a variable allocation to volatility based on mean-reversion. In addition to these academic studies, we identified a relevant volatility product currently being sold that makes use of a strategic allocation rule. The Barclays ETN+ VEQTOR S\&P 500 Linked ETN has been linked to the performance of the S\&P 500 Dynamic VEQTOR Index, which dynamically allocates between equity and volatility based on a combination of realized and implied volatility trend decision rules.

In general, the proposed strategic allocations to volatility seem to be either based on mean reversion trend assumptions, on implied volatility trend assumptions, or on recent levels of realized volatility. These concepts will also be the basis for our analyses on volatility diversification strategies in Subsection IV-B.

\section{METHODOLOGY}

The basic concept of the diversification study is to test whether, under what circumstances, and employing which implementation strategies, the addition of volatility exposure to equity portfolios would benefit retail investors. With this objective, we broadly backtest the effects of various volatility allocations on portfolio metrics over the 6-year period from 2006 to 2011.

\section{A. Approach}

First, we conduct an extensive backtesting of volatilitydiversified equity portfolios. Initially, comprehensive sensitivity tables for key portfolio metrics (portfolio return, portfolio volatility, portfolio Sharpe ratio) are calculated, resulting from variations in the allocations to volatility ETNs from $0 \%$ to $100 \%$. The remainder of the portfolio weight (i.e., $100 \%$ minus volatility weight) is allocated to the equity ETF. To ensure robustness of results and to be able to interpret different influencing factors, a number of variations are calculated: the volatility products are varied by maturities of the underlying VIX futures (short-term and mid-term), the evaluation periods are varied (full sample period from 2006 to 2011 and post-crisis sample period from 2009 to 2011), and the rebalancing patterns are varied (no rebalancing, monthly rebalancing, and daily rebalancing).

The broad-based sensitivity tables already yield insights on the usability and relative performance of different volatility products. The sensitivity tables and the additional diversification analyses over time jointly allow for assessing the benefits of volatility diversification in equity portfolios. Correspondingly, the proposed hypotheses of the study's first research area read as follows:

Hypothesis 1-1: Appropriate volatility product selection is vital for successful volatility diversification. 
Hypothesis 1-2: Volatility diversification would have benefited retail investors over the period from 2006 to 2011.

Second, we test three volatility-diversification strategies regarding their ability to better derive volatility allocation weights relative to a non-strategic, purely calendar-based monthly rebalancing. Based on a literature review and analyzing methodologies that govern actual dynamic volatility products (see Section II), we identified three strategy concepts that seem worthwhile to be evaluated: implied volatility trend following (IV), implied volatility mean reversion (MR), and realized volatility clustering $(\mathrm{RV})$.

We then, based on the examples in the literature and practice where available, designed rules that implement the strategies based on trailing and leading indicators in the data. As a benchmark for the strategies, a non-strategic, purely calendarbased monthly rebalancing scheme to normal target weights of $10 \%$ volatility exposure is used. The strategies are set to adjust the normal target weight, while on average a target weight equal to the normal target weight is maintained with the help of a weighting factor in each formula. This ensures comparisons on a leveled basis both between the strategies and the benchmark. Additionally, all volatility target weights are set to be range-bound between 0 and $100 \%$ to prohibit short-selling. The rules behind each strategy are as follows (the implementation formulas are given in the explanation below Table III):

IV-Strategy: detect trends in the level of implied volatility, assume continuity and adjust volatility target weights accordingly

MR-Strategy: detect deviations of implied volatility from historical mean, assume mean reversion and adjust weights accordingly.

$R V$-Strategy: detect the current level of realized volatility relative to historical mean, assume volatility clustering and adjust weights accordingly.

Comparatively backtesting these strategies will enable us to evaluate the following hypotheses we propose for this second part of our diversification study:

Hypothesis 2-1: The Implied Volatility Trend Strategy would have benefited retail investors' volatility diversification over the period from 2006 to 2011.

Hypothesis 2-2: The Implied Volatility Mean Reversion Strategy would have benefited retail investors' volatility diversification over the period from 2006 to 2011.

Hypothesis 2-3: The Realized Volatility Clustering Strategy would have benefited retail investors' volatility diversification over the period from 2006 to 2011.

\section{B. Data}

To represent equities in our analyses, we use the S\&P 500 index (SPX), for which data have been obtained from Datastream. To keep the study as realistic as possible, not the index itself but a popular investable ETF tracking the index will be used in the backtestings representing the equity part of the portfolios, namely the SPDR S\&P 500 (SPY), for which historical data has been obtained from the SPDR State Street Global Advisors website (www.spdrs.com).

Volatility as an asset class, is represented by the VIX index. Historical VIX data has been obtained from Datastream. With respect to products used to simulate long exposure to equity volatility, we select ETNs due to their popularity with retail investors and their underrepresentation in empirical studies to date. We use two ETNs with different maturities in order to be able to analyze the implications of using longer or shorter term ETNs, which, as mentioned above, could make an important difference. As a short-term volatility futures product, the iPath S\&P 500 VIX Short-Term Futures ETN, ticker VXX, will be used. For the sake of a longer data history, the underlying index S\&P 500 VIX Short-Term Futures Index will be used before the ETNs launch and adjusted for the difference in investor fees between index and ETN, which amounts to $0.89 \%$ p.a. (SPVXSTR adj). As a mid-term volatility futures product, the iPath S\&P 500 VIX Mid-Term Futures ETN (VXZ) will be used, again represented before its launch by its underlying index S\&P 500 VIX Mid-Term Futures Index and adjusted for investor fees (SPVXMTR adj). See [25] for details on both volatility futures ETNs, and [26] and [27] for details on the volatility futures indices. Historical data for the ETNs have been obtained from iPath (www.ipathetn.com). Historical indices data have been placed at the authors' disposal by courtesy of Standard \& Poor's.

Two sample periods will be looked at: (1) a full sample period, which extends over 6 years from December 20, 2005 (the day the S\&P 500 VIX Futures Index Series commences) to December 20, 2011; and (2) a shorter, post-crisis sample period that extends over 3 years from December 20, 2008 to December 20, 2011. Since the character of the full sample period is dominated by the occurrence of the 2008 financial crisis, the second shorter sample period, which covers the postcrisis phase from 2009 to 2011, is deemed interesting to be analyzed comparatively.

Descriptive summary statistics on equity index, equity ETF, volatility index, and volatility ETNs over both sample periods are presented in Table I below:

TABLE I. DESCRIPTIVE SUMMARY STATISTICS

\begin{tabular}{|c|c|c|c|c|c|c|}
\hline & SPX & SPY & VIX & 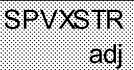 & V \\
\hline \multirow{3}{*}{$\begin{array}{l}\text { return } \\
\text { vol } \\
\text { sharpe }\end{array}$} & \multirow{3}{*}{$\begin{array}{c}2006- \\
2011\end{array}$} & $1.89 \%$ & $0.24 \%$ & $12.94 \%$ & $28.03 \%$ & $5.54 \%$ \\
\hline & & $24.66 \%$ & $24.58 \%$ & $120.11 \%$ & $61.89 \%$ & $32.52 \%$ \\
\hline & & 0.08 & ( & 0.11 & : $:$ : $1 / \mathrm{m}$ & 0.17 \\
\hline \multirow{3}{*}{$\begin{array}{l}\text { return } \\
\text { vol } \\
\text { sharpe }\end{array}$} & \multirow{3}{*}{$\begin{array}{c}2009- \\
2011\end{array}$} & $14.29 \%$ & $11.85 \%$ & $-19.75 \%$ & $56.49 \%$ & $16.20 \%$ \\
\hline & & $23.21 \%$ & $23.17 \%$ & $118.01 \%$ & $65.56 \%$ & $33.04 \%$ \\
\hline & & 0.62 & 0.51 & $\mathrm{n} / \mathrm{m}$ & : $: 19 / m$ & . \\
\hline \multirow{6}{*}{ returns } & 2006 & $15.18 \%$ & $12.98 \%$ & $-8.31 \%$ & $52.11 \%$ & $21.05 \%$ \\
\hline & 2007 & $4.54 \%$ & $3.11 \%$ & $100.58 \%$ & $45.05 \%$ & $54.41 \%$ \\
\hline & 2008 & $-37.77 \%$ & $39.52 \%$ & $118.32 \%$ & $142.78 \%$ & $92.58 \%$ \\
\hline & 2009 & $27.28 \%$ & $24.33 \%$ & $-51.75 \%$ & $67.54 \%$ & $24.84 \%$ \\
\hline & 2010 & $15.41 \%$ & $13.09 \%$ & $-24.31 \%$ & $73.62 \%$ & $20.28 \%$ \\
\hline & 2011 & $1.64 \%$ & $0.49 \%$ & $41.50 \%$ & $-3.81 \%$ & $-1,78 \%$ \\
\hline
\end{tabular}

This table provides summary statistics on the assets in the investment universe used in the diversification backtesting (shaded in grey) as well as for related indices. Portfolio statistics shown include return p.a. and volatility p.a. Sharpe ratios (assuming a risk-free interest rate of zero) are also calculated where positive; negative Sharpe ratios are not meaningful (indicated as $\mathrm{n} / \mathrm{m}$ ), since higher risk leads to higher (i.e., less negative) ratios. Statistics are given for the full sample period from 2006 
to 2011 (December 20, 2005 to December 20, 2011) as well as for the post-crisis sample period from 2009 to 2011 (December 20, 2008 to December 20, 2011) separately.

\section{RESULTS}

Backtesting results of volatility diversifications in equity portfolios are presented in subsection A, evaluations of dynamic volatility diversification strategies are shown in subsection B.

\section{A. Volatility diversification of equity portfolios}

To begin with, a typical cquity portfolio, represented by the SPDR S\&P 500 ETF (SPY), is backtested with a portfolio weight allocated to the volatility products S\&P 500 VIX ShortTerm Futures Index, adjusted for investor fees (SPVXSTR adj), and S\&P 500 VIX Mid-Term Futures Index, adjusted for investor fees (SPVXMTR adj), representing short-term futuresbased volatility ETNs and mid-term futures-based volatility ETNs, respectively. The resulting key portfolio metrics for the full range of possible volatility weights $(0 \%$ to $100 \%)$, for the two different volatility maturities (short-term and mid-term), and for the two different sample periods (full and post-crisis) are shown by the sensitivity measures in Table II:

TABLE II. S SENSITIVITY MEASURES OF PORTFOLIO DIVERSIFICATION THROUGH VOLATILITY

\begin{tabular}{|c|c|c|c|c|c|c|c|c|c|c|c|c|c|}
\hline \multirow{3}{*}{\multicolumn{2}{|c|}{$\begin{array}{l}\text { metric } \\
\text { sample period } \\
\text { ETN maturity } \\
\end{array}$}} & \multicolumn{4}{|c|}{ portfolio return p.a. } & \multicolumn{4}{|c|}{ portfolio volatility p.a. } & \multicolumn{4}{|c|}{ Sharpe ratio } \\
\hline & & \multicolumn{2}{|c|}{ full } & \multicolumn{2}{|c|}{ post-crisis } & \multicolumn{2}{|c|}{ full } & \multicolumn{2}{|c|}{ post-crisis } & \multicolumn{2}{|c|}{ full } & \multicolumn{2}{|c|}{ post-crisis } \\
\hline & & short-term & mid-term & short-term & mid-term & short-term & mid-term & short-term & mid-term & short-term & mid-term & short-term & mid-term \\
\hline \multirow{22}{*}{ 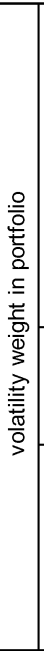 } & $0 \%$ & $0.24 \%$ & $0.24 \%$ & $18.85 \%$ & $1185 \%$ & $24.58 \%$ & $24.58 \%$ & $23.17 \%$ & $23.17 \%$ & $\mathrm{n} / \mathrm{m}$ & $\mathrm{n} / \mathrm{m}$ & 0.512 & O. 551 \\
\hline & $1 \%$ & $0.08 \%$ & $0.03 \%$ & $1122 \%$ & $11.63 \%$ & $23.73 \%$ & $24.03 \%$ & $22.33 \%$ & $22.65 \%$ & $\mathrm{n} / \mathrm{m}$ & $\mathrm{n} / \mathrm{m}$ & 650 & 6.51 \\
\hline & $2 \%$ & $0.06 \%$ & $0.18 \%$ & $10.8 \% \%$ & $1.1 .1 .8 \%$ & $22.90 \%$ & $23.50 \%$ & $21.50 \%$ & $22.13 \%$ & 0.00 & 0.01 & (1). 49 & (0.5: \\
\hline & $3 \%$ & $0.19 \%$ & $0.39 \%$ & $=0.98 .1 \%$ & $1.124 \%$ & $22.08 \%$ & $22.96 \%$ & $20.69 \%$ & $21.61 \%$ & 0.01 & 0.02 & 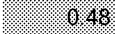 & 0.52 \\
\hline & $4 \%$ & $0.31 \%$ & $0.59 \%$ & $9.80 \%$ & (1:08\% & $21.27 \%$ & $22.43 \%$ & $19.88 \%$ & $21.10 \%$ & 0.01 & 0.03 & 0.7. & 0.52 \\
\hline & $5 \%$ & $0.41 \%$ & $0.79 \%$ & $8.84 \%$ & 10.820. & $20.48 \%$ & $21.90 \%$ & $19.10 \%$ & $20.58 \%$ & 0.02 & 0.04 & 0.45 & 0.58 \\
\hline & $6 \%$ & $0.49 \%$ & $0.98 \%$ & $7.98 \%$ & $10.61 \%$ & $19.71 \%$ & $21.37 \%$ & $18.32 \%$ & $20.08 \%$ & 0.03 & 0.05 & (0.8.4. & 0.53 \\
\hline & $7 \%$ & $0.57 \%$ & $17 \%$ & $1.1 \% 1 \%$ & $10.40 \%$ & $18.95 \%$ & $20.85 \%$ & $17.57 \%$ & $19.57 \%$ & 0.03 & 0.06 & 0.42 & 0.53 \\
\hline & $8 \%$ & $0.63 \%$ & $136 \%$ & $6.04 \%$ & $10.18 \%$ & $18.22 \%$ & $20.34 \%$ & $16.83 \%$ & $19.07 \%$ & 0.03 & 0.07 & 0.39 & 0.83 \\
\hline & $9 \%$ & $0.67 \%$ & $155 \%$ & $5.96 \%$ & 9.97. & $17.50 \%$ & $19.82 \%$ & $16.12 \%$ & $18.57 \%$ & 0.04 & 0.08 & 0.37 & 0.54 \\
\hline & $10 \%$ & $0.71 \%$ & $1,73 \%$ & $5.28 \%$ & $9.75 \%$ & $1688 \%$ & $19.32 \%$ & $15.43 \%$ & $1808 \%$ & 0.04 & 0.09 & 0.34 & 0.54 \\
\hline & $15 \%$ & $0.69 \%$ & $2.58 \%$ & $1.80 \%$ & 8.619. & $13.7 \%$ & $1686 \%$ & $1282 \%$ & $1568 \%$ & 0.05 & 0.15 & 0.14 & 6.55 \\
\hline & $20 \%$ & $0.39 \%$ & $3,36 \%$ & $1.78 \%$ & $1: 430$. & $.1 .1 .1 \%$ & $14.57 \%$ & $10.55 \%$ & $13.4 .4 \%$ & 0.03 & 0.23 & $\mathrm{n} / \mathrm{m}$ & (0.5. \\
\hline & $25 \%$ & $-0.17 \%$ & $4.05 \%$ & $-5.42 \%$ & $6.10 \%$ & $1.1 .09 \%$ & $12.32 \%$ & 10.89. & $1.12 .2 \%$ & $\mathrm{n} / \mathrm{m}$ & 0.32 & $\mathrm{n} / \mathrm{m}$ & (3. 5. \\
\hline & $30 \%$ & $0.98 \%$ & $4.66 \% \%$ & $-9.10 \%$ & $4.92 \%$ & $12.05 \%$ & $10.81 \%$ & $1.93 \%$ & $9.1 .7 \%$ & $\mathrm{n} / \mathrm{m}$ & 0.43 & $\mathrm{n} / \mathrm{m}$ & 0.50 \\
\hline & $40 \%$ & $3.24 \%$ & $5.64 \%$ & $16.50 \%$ & $2.24 \%$ & $17.13 \%$ & $9013 \%$ & $17.92 \%$ & (3. $14 \%$ & $\mathrm{n} / \mathrm{m}$ & 6.62 & $\mathrm{n} / \mathrm{m}$ & 0.27 \\
\hline & $50 \%$ & $6.23 \%$ & ( $6.320 .1 \%$ & $-23.84 \%$ & $0.59 \%$ & $23.95 \%$ & $10.42 \%$ & $25.33 \%$ & $10.03 \%$ & $\mathrm{n} / \mathrm{m}$ & 0.61 & $\mathrm{n} / \mathrm{m}$ & $\mathrm{n} / \mathrm{m}$ \\
\hline & $60 \%$ & $-9.82 \%$ & 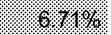 & $-31.01 \%$ & $3.53 \%$ & $31.30 \%$ & $1.8 .81 \%$. & $33.16 \%$ & $13.7 .4 \%$ & $\mathrm{n} / \mathrm{m}$ & 0.49 & $\mathrm{n} / \mathrm{m}$ & $\mathrm{n} / \mathrm{m}$ \\
\hline & $70 \%$ & $-13.90 \%$ & $6.8 .18 \%$ & $-37.92 \%$ & $-6.59 \%$ & $38.85 \%$ & $18.10 \%$ & $41.15 \%$ & $18.23 \%$ & $\mathrm{n} / \mathrm{m}$ & 0.38 & $\mathrm{n} / \mathrm{m}$ & $\mathrm{n} / \mathrm{m}$ \\
\hline & $80 \%$ & $18.36 \%$ & $6.64 \%$ & $-44.50 \%$ & $-9.73 \%$ & $46.48 \%$ & $22.77 \%$ & $49.23 \%$ & $23.04 \%$ & $\mathrm{n} / \mathrm{m}$ & 0.29 & $\mathrm{n} / \mathrm{m}$ & $\mathrm{n} / \mathrm{m}$ \\
\hline & $90 \%$ & $-23.10 \%$ & $6.21 \%$ & $-50.70 \%$ & $12.94 \%$ & $54.17 \%$ & $27.60 \%$ & $57.36 \%$ & $28.00 \%$ & $\mathrm{n} / \mathrm{m}$ & 0.23 & $\mathrm{n} / \mathrm{m}$ & $\mathrm{n} / \mathrm{m}$ \\
\hline & $100 \%$ & $-28.03 \%$ & $5.3 .5 \%$ & $-56.49 \%$ & $-16.20 \%$ & $61.89 \%$ & $32.52 \%$ & $65.56 \%$ & $33.04 \%$ & $\mathrm{n} / \mathrm{m}$ & 0.17 & $\mathrm{n} / \mathrm{m}$ & $\mathrm{n} / \mathrm{m}$ \\
\hline
\end{tabular}

This table reports portfolio metrics for a volatility-diversified equity portfolio. Equities are represented by the SPDR S\&P 500 ETF (SPY); volatility is represented by the adjusted S\&P 500 VIX Short-Term Futures Index (SPVXSTR adj) and the adjusted S\&P 500 VIX Mid-Term Futures Index (SPVXMTR adj) for short-term ETN maturity and mid-term ETN maturity, respectively. Portfolio weights are rebalanced monthly. Sample periods reported are the full sample period from 2006 to 2011 (December 20, 2005 to December 20,2011) and the post-crisis sample period from 2009 to 2011 (December 20, 2008 to December 20, 2011). Portfolio metrics reported are the portfolio return p.a., the portfolio volatility p.a., and the portfolio Shape ratio. The Sharpe ratios are calculated assuming a risk-free interest rate of zero and are displayed only when positive; negative Sharpe ratios are not meaningful (indicated as $\mathrm{n} / \mathrm{m}$ ), since higher risk leads to higher (i.e., less negative) ratios. For increased readability, more favorable values are shaded in darker grey.

A couple of insights can be drawn from the sensitivity tables above. First, backtesting results vary with test settings, in particular with the sample period evaluated; this was the reason for using two alternative sample periods in the first place. The ex post optimal portfolio weights allocated to volatility are - ceteris paribus - larger for the full sample period than for the post-crisis sample period. It comes as no surprise that volatility exposure benefits a portfolio to a greater extent during the full sample period, which is characterized by the occurrence of the 2008 financial crisis, than during the post-crisis sample period, which overall is much calmer. Further longitudinal analyses of market condition effects not shown here confirm this notion of varying benefits of volatility hedging depending on market conditions: Portfolio returns are typically lower during upward trending markets due to the described contango effect and higher during downward trending markets, periods of rising market uncertainty, and especially market crises.

With respect to portfolio volatility, we find that volatility products are able to reduce portfolio volatility throughout the entire sample period, however, to a varying extent depending on market conditions. Empirical evidence suggests that during adverse markets, the diversification effect is most pronounced. This can be explained by the reported asymmetric correlation profile of the volatility products, which tends to make them more (inversely) reactive to falls in the equity market than to increases; see [2], [6], [14], [16], and [21].

When considering the effects on portfolio returns and volatilities simultaneously by looking at Sharpe ratios, the likely positive effect of adding volatility to equity portfolios is backed. While the portfolio benefits only during adverse markets, volatility is reduced under all market conditions; 
consequently, the risk-adjusted performance, as evidenced by the Sharpe ratios, is enhanced most of the time.

Second, we find evidence that the use of mid-term ETNs yields superior results to those produced by using short-term ETNs. The reason can be traced back to the stronger contango drag on short-term ETNs. However, the drawback with midterm ETNs is that they exhibit a less effective diversification effect than short-term ETNs. This translates into slightly higher portfolio volatility measures in the backtesting results for most portfolios using mid-term ETNs than for those using short-term ETNs. When considering the effects on portfolio returns and volatilities simultaneously, however, comparing Sharpe ratios gives a clear message in favor of the mid-term ETNs. The strong contango drag on short-term ETNs is not fully compensated through the only slightly better diversification properties. Hence, for most investors and scenarios, using mid-term ETNs may be the better choice. Still, for highly risk-averse investors or if one assumes a sufficiently short and turbulent holding period of volatility ETNs, the short-term ETNs might benefit the portfolio to a greater extent.

To sum up, backtested equity portfolios benefit most from the addition of volatility products during crises, adverse markets and (increasing) uncertainty in the market. However, mid-term futures ETNs, which are not subject to high contango drag, remain beneficial during most of the time and/or for strongly risk-adverse investors that are willing to accept a severe drag on upside potential in exchange for portfolio risk reduction. Timing the market therefore becomes an option, but not a must in order to successfully invest in volatility using these products. Since mid-term volatility ETNs could be documented to benefit an equity portfolio in many scenarios and most circumstances, first and foremost during the financial crisis, Hypothesis 1-2 cannot be rejected.

Moreover, due to the significant differences in results caused by the selection of volatility products, it is imperative that retail investors understand the products' constructions (in particular the implications of the maturities of the underlying futures) and resulting behaviors. Otherwise, they will not be able to take an informed decision with respect to product selection based on investment objectives, risk aversion, investment horizon and expected market development. Consequently, Hypothesis 1-1 cannot be rejected.

\section{B. Volatility diversification using dynamic allocation strategies}

Comparing the portfolio statistics of the three dynamic volatility allocation strategies to the equity-only, and in particular to the directly comparable monthly rebalancing scheme in Table III yields the relative additional value that they provide to be estimated. The evidence clearly suggests that the IV-Strategy enhances the portfolio statistics. Especially portfolio returns are increased strongly, while the volatilities of the portfolio returns are slightly reduced relative to the benchmarks. Consequently, portfolio Sharpe ratios, as measures of risk-adjusted performance, increase strongly.

Contrary to the successful IV-Strategy, however, both the MR-Strategy and the RV-Strategy do not seem to benefit their respective equity portfolios in the backtestings. The MRStrategy even exhibits some slightly deteriorated portfolio statistics relative to the benchmarks. The RV-Strategy slightly improves some statistics, however, only marginally and not consistently for both sample periods.

One possible interpretation for why the IV-Strategy that is based on implied volatility works better than the RV-Strategy based on realized volatility is the difference in perspective. Implied volatility is considered a leading indicator in reflecting expected future volatility, while realized volatility is considered a trailing indicator reflecting past volatility. Hence, the strategy based on implied volatility may be relatively quicker to respond to changes in market sentiment and to adjust allocations accordingly in a timelier manner. The failure of the MR-Strategy may be due to the long-term nature of volatility mean reversion. Therefore, in the relatively shortterm monthly rebalancing pattern, the mean reversion trend does not show its effect.

Based on these weak results of the MR-Strategy and the RV-Strategy relative to their benchmarks, Hypothesis 2-2 and Hypothesis 2-3 have to be rejected.

With respect to Hypothesis 2-1 on the Implied Volatility Trend Strategy, given the promising results shown, we added longitudinal analyses (not shown) to gain additional insights on the suitability during crises of the IV-Strategy.

TABLE III. DynAmic Volatility ALLOCATION STRATEgIES ANALYSIS

\begin{tabular}{|c|c|c|c|c|c|c|c|c|c|}
\hline & equity only. & monthly re & lancing. & IV-Str & egy & MR-S & ategy & RV-St & ategy \\
\hline SPY weight & $1.100 \%$ & ( $.90 \%$ & $90 \%$ & $90 \%-\mathrm{IV}$ & $90 \%-\mathrm{IV}$ & $90 \%-M R$ & $90 \%-M R$ & $90 \%-\mathrm{RV}$ & $90 \%-\mathrm{RV}$ \\
\hline SPVXSTR adj weight & $: 0 \%$ & $10 \%$ & $0 \%$ & $10 \%+\mathrm{IV}$ & $0 \%$ & $10 \%+\mathrm{MR}$ & $0 \%$ & $10 \%+R V$ & $0 \%$ \\
\hline SPVXMTR adj weight & $0 \%$ & $0 \%$ & $10 \%$ & $0 \%$ & $10 \%+\mathrm{IV}$ & $0 \%$ & $10 \%+M R$ & $0 \%$ & $10 \%+R V$ \\
\hline return p.a. 2006-2011 & $0.24 \%$ & $0.7 \% \%$ & $1.73 \%$ & $9.72 \%$ & $6.84 \%$ & $0.94 \%$ & $1.07 \%$ & $1.27 \%$ & $2.20 \%$ \\
\hline volatility p.a. & $24.58 \%$ & $16.81 \%$ & $19.32 \%$ & $15.92 \%$ & $17.33 \%$ & $22.52 \%$ & $22.86 \%$ & $15.89 \%$ & $18.64 \%$ \\
\hline Sharpe ratio & : $1 / \mathrm{m}$ & $: 0.04$ & 0.09 & 0.61 & 0.39 & 0.04 & 0.05 & 0.08 & 0.12 \\
\hline return p.a. 2009-2011 & $11.85 \%$ & $5.28 \%$ & $9.75 \%$ & $8.29 \%$ & $10.74 \%$ & $14.64 \%$ & $13.60 \%$ & $4.87 \%$ & $9.62 \%$ \\
\hline volatility p.a. & $23.17 \%$ & $15.43 \%$ & $18.08 \%$ & $16.91 \%$ & $18.62 \%$ & $20.30 \%$ & $21.11 \%$ & $14.91 \%$ & $17.73 \%$ \\
\hline Sharpe ratio & 0.51 & 0.34 & 0.54 & 0.49 & 0.58 & 0.72 & 0.64 & 0.33 & 0.54 \\
\hline
\end{tabular}

This table provides summary statistics of an equity-only portfolio, a monthly rebalanced $90 \% / 10 \%$-portfolio, and three strategically rebalanced portfolios throughout the full sample period (December 20, 2005 to December 20,2011) and the post-crisis sample period (December 20, 2008 to December 20, 2011). Equities are represented by SPDR S\&P 500 ETF, volatility is represented by the adjusted S\&P 500 VIX Short- and Mid-Term Futures Indices. Portfolio statistics of three dynamic volatility allocation strategy overlays, that adjust the basic $90 \% / 10 \%$ allocation according to preset rules, are provided: Implied Volatility Trend Strategy: IV $=0.8 \times((5-$ day rolling average of VIX / 20-day rolling average of VIX)-1); Implied Volatility Mean Reversion Strategy: MR $=0.4 \times(($ current VIX/historical average of VIX) -1$)$; Realized Volatility Clustering Strategy: RV=0.01×((current SPY volatility/historical average of SPY volatility)-1). Sharpe ratios (assuming a risk-free interest rate of zero) are calculated where positive; negative Sharpe ratios are not meaningful (indicated as $\mathrm{n} / \mathrm{m}$ ), since higher risk leads to higher (i.e., less negative) ratios. 
During 2008, the IV-Strategy is able to increase the allocation to volatility in a timely manner so that the equity drawdown is efficiently mitigated. Hence, the intended equityhedge through volatility allocation in the equity portfolio works out very well. In the following months, the exposure to volatility is reduced again, so that the futures' contango drag on the upside is limited during the recovery period.

In sum, due to the positive effects on portfolio statistics over the sample period and due to the effective downside protection displayed in 2008, Hypothesis 2-1 cannot be rejected.

\section{CONCLUSIONS}

Volatility as an asset class is currently extolled as a valuable portfolio diversifier. We analyze if, under what circumstances, and employing which implantation strategies, this is actually true for retail investors. While we find evidence supporting the possibility of successfully translating the theoretical concept of volatility as an asset class into actually tradable products for retail investors and confirm that the diversification-relevant properties have not been lost through translation, a number of issues need to be understood and considered when selecting an appropriate volatility product.

First, selecting the appropriate investable volatility product with respect to maturity seems decisive. Second, we show that the market conditions play an important role as to when volatility exposure benefits or hurts a portfolio. Third, with respect to implementing a volatility strategy, we show that applying a dynamic allocation strategy, based on the detection of trends in implied volatility, may strongly benefit the portfolio relative to a pure calendar-based rebalancing.

Limitations of this portfolio diversification study include that, given the myriad of possible constellations of backtesting methodologies, samples, approaches, test settings, and evaluation metrics, every study can only cover a rather specific, non-exhaustive problem.

Possible extensions of this research could include exploring further volatility products; e.g., futures-based products that differ in the underlying volatility indices or in their design. Also, the addition of volatility to other asset classes than equity should prove worthwhile to backtest.

Overall, it could be shown that volatility can be seen as an asset class in its own right. Especially in times of seemingly endless market crisis and financial turmoil, volatility as a truly negatively correlated asset class certainly deserves a place in the investment opportunity set and will prove useful, as long as the downsides are equally acknowledged and reduced through potentially better products. To date, the difference in performance between spot volatility and derived futures-based volatility products is large and must be kept in mind by investors, since volatility is promoted all too often using spot indices to represent volatility as an asset class. Also, the current common conception of ETNs as being convenient investment instruments is misleading, since, although they appear simple, in reality they are highly complex financial products that are more difficult to make use of than the financial industry would like retail investors to believe.

\section{REFERENCES}

[1] E. Szado, "VIX futures and options: A case study of portfolio diversification during the 2008 financial crisis", Journal of Alternative Investments, vol. 12, no. 2, pp. 68-85, 2009.

[2] J. R. DeLisle, J. S. Doran, and K. Krieger, "Volatility as an asset class: Holding VIX in a portfolio", 2010, unpublished.

[3] M. Kolanovic, D. Silvestrini, T. S. Lee, and M. Naito, "Rise of crossasset correlations - asset class roadmap for equity investors". Global Equity Derivatives \& Delta One Strategy. J.P.Morgan, New York, 2011.

[4] R. D. Stock, "The evolution of the risk trade: Volatility as an asset class". Research Report. Spruce Private Investors, Stamford, 2011.

[5] C. Alexander, and D. Korovilas, "The hazards of volatility diversification", 2011, unpublished.

[6] G. Giese, "Volatility as an asset class". Research Report. STOXX, Zurich, 2010.

[7] R. Huebscher, "Volatility as an asset class". Research Report. Advisor Perspectives, 2009.

[8] B. Liu, and S. Dash, "Access to volatility via listed futures". Research \& Design. Standard \& Poor's, New York, 2010.

[9] R. E. Whaley, "Derivatives on market volatility: Hedging tools long overdue", Journal of Derivatives, vol. 1, no. 1, pp. 71-84, 1993.

[10] R. E. Whaley, "The investor fear gauge", Journal of Portfolio Management, vol. 26, no. 3, pp. 12-17, 2000.

[11] Chicago Board Options Exchange, "The CBOE volatility index - VIX". White Paper. Chicago Board Options Exchange, Chicago, 2009

[12] B. Luby, "Slicing and dicing all 31 flavors of the VIX ETPs", URL: http//vixandmore blogspotcomi201/1/ten-months-have-passed. since-last time html. Accessed: 2011-12-31.

[13] B. Bowler, H. Ebens, J. Davi, and M. Kolanovic, "Volatility - the perfect asset?". Merill Lynch Global Securities Research and Economics Group Research Report. Merrill Lynch, New York, 2003.

[14] R. T. Daigler, and L. Rossi, "A portfolio of stocks and volatility", Journal of Investing, vol. 15, no. 2, pp. 99-106, 2006.

[15] M. Sloyer, and R. Tolkin, "The VIX as a fix: Equity volatility as a lifelong investment enhancer", 2008, unpublished.

[16] S. Dash, and M. T. Moran, "VIX as a companion for hedge fund portfolios", Journal of Alternative Investments, vol. 8, no. 3, pp. 75-80, 2005.

[17] C. W. Stanton, "Volatility as an asset class - the potential of the VIX as a hedging tool and the shortcomings of VIX exchange-traded notes", Journal of Investment Consulting, vol. 12, no. 1, pp. 23-30, 2011.

[18] M. T. Moran, and S. Dash, "VIX futures and options pricing and using volatility products to manage downside risk and improve efficiency in equity portfolios", Journal of Trading, vol. 2, no. 3, pp. 96-105, 2007.

[19] B. Lee, and Y.-N. Lin, "Using volatility instruments as extreme downside hedges", 2010, unpublished.

[20] O. Signori, M. Briere, and A. Burgues, "Volatility exposure for strategic asset allocation", Journal of Portfolio Management, vol. 36, no. 3, pp. $105-116,2010$.

[21] D. Cheeseman, H. Ebens, M. Yang, C. Kotecha, and B. Kaplan, "VIX futures and options". Equity Derivatives Research Report. Merrill Lynch, New York, 2008.

[22] M. K. McCarty, "VIX futures in focus", URL:

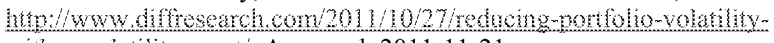
With-a-yolatility-asset. Accessed: 2011-11-21.

[23] H.-C. Chen, S.-L. Chung, and K.-Y. Ho, "The diversification effects of volatility-related assets", Journal of Banking \& Finance, vol. 35, no. 5, pp. 1179-1189, 2011.

[24] J. Pézier, and A. White, "The relative merits of alternative investments in passive portfolios", Journal of Alternative Investments, vol. 10, no. 4, pp. 37-49, 2008.

[25] iPath, "Ipath volatility etns". iPath Volatility ETNs Prospectus. Barclays, London, 2011.

[26] Standard \& Poor's, "S\&P 500 VIX futures index series". Fact Sheet. Standard \& Poor's, New York, 2011.

[27] Standard \& Poor's, "S\&P 500 VIX futures indices methodology". Index Methodology. Standard \& Poor's, New York, 2011. 
Prof. Dr. Pascal Gantenbein, MRICS, is the HenriB.-Meier Professor of Financial Management at University of Basel's Center of Economic Sciences (WWZ). His academic activities are in the areas of corporate finance, portfolio management, risk management, real estate finance, and venture finance. He has been involved with many academic institutions worldwide and has also been working in the insurance sector and on real estate projects.

Dr. Andreas Rehrauer was a Ph.D. student under supervision of Prof. Dr. Pascal Gantenbein at the Henri-B.-Meier Department of Financial Management at University of Basel's Center of Economic Sciences (WWZ). His academic activities are in the areas of corporate finance, corporate governance and portfolio management. He has gained professional experience in asset management, investment banking and management consulting. 